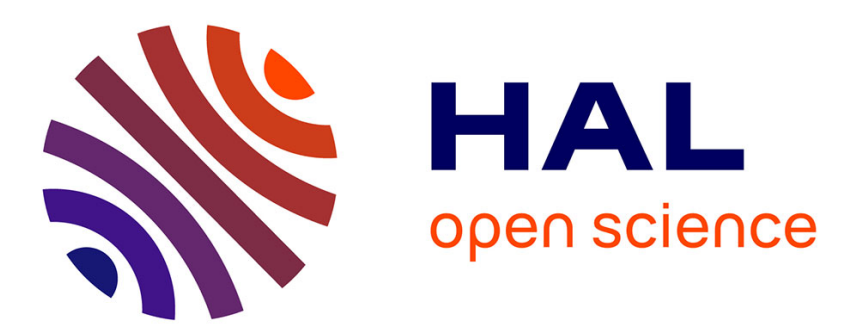

\title{
Study of the dielectric properties of disperse micro-crystals of ice near the melting temperature. Section I : experimental results
}

B. Lagourette

\section{- To cite this version:}

B. Lagourette. Study of the dielectric properties of disperse micro-crystals of ice near the melting temperature. Section I: experimental results. Journal de Physique, 1976, 37 (7-8), pp.945-954. 10.1051/jphys:01976003707-8094500 . jpa-00208490

\section{HAL Id: jpa-00208490 https://hal.science/jpa-00208490}

Submitted on 1 Jan 1976

HAL is a multi-disciplinary open access archive for the deposit and dissemination of scientific research documents, whether they are published or not. The documents may come from teaching and research institutions in France or abroad, or from public or private research centers.
L'archive ouverte pluridisciplinaire HAL, est destinée au dépôt et à la diffusion de documents scientifiques de niveau recherche, publiés ou non, émanant des établissements d'enseignement et de recherche français ou étrangers, des laboratoires publics ou privés. 


\title{
STUDY OF THE DIELECTRIC PROPERTIES OF DISPERSE MICRO-CRYSTALS OF ICE NEAR THE MELTING TEMPERATURE. SECTION I : EXPERIMENTAL RESULTS
}

\author{
B. LAGOURETTE \\ Laboratoire de Thermodynamique, Institut Universitaire de Recherche Scientifique, \\ Université de Pau et des Pays de l'Adour, B.P. 523 (Pau-Université), 64010 Pau, France
}

(Reçu le 16 février 1976, accepté le 23 mars 1976)

\begin{abstract}
Résumé. - Les propriétés diélectriques de dispersions de micro-cristaux de glace obtenue par voie irréversible ont été étudiées en fonction de la teneur en glace dispersée, de la nature du support émulsionnant et de la température dans un domaine de fréquence $20 \mathrm{~Hz}-3 \mathrm{MHz}$.

En plus du domaine de relaxation dû à l'absorption dipolaire Debye de la glace, on observe, à des fréquences plus basses, d'autres domaines de relaxation dont les dimensions augmentent avec la température.
\end{abstract}

\begin{abstract}
The dielectric properties of the dispersions of ice micro-crystals obtained by an irreversible process have been studied as a function of the percentage of disperse ice, of the nature of the emulsion mixture and of the temperature within a frequency range from $20 \mathrm{~Hz}$ to $3 \mathrm{MHz}$.

In addition to the range of relaxation produced by the Debye dipolar absorption of ice, further ranges whose amplitude increases along with temperature can be observed at lower frequencies.
\end{abstract}

1. Introduction. - Through supercooling breakdown of water droplets emulsified within an appropriate medium, it is possible to obtain dispersions of ice micro-crystals formed by an irreversible process.

Previous works $[1,2,3]$ have been devoted to the study of the complex relative permittivity $\varepsilon^{*}=\varepsilon^{\prime}-j \varepsilon^{\prime \prime}$ of such dispersions within the frequency range [1 $\mathrm{kHz}-3 \mathrm{MHz}]$ at temperatures generally lower than $-20^{\circ} \mathrm{C}$. A dielectric relaxation whose properties change in course of time has been observed [1,2]. It has been shown [3] that this relaxation can be attributed to the Debye dipolar absorption of the disperse ice, the phenomenon of evolution being accounted for by a transformation from solid to solid connected with the existence of a microstructure of ice [4].

With a view to complementing the works previously achieved, we have studied the dielectric properties of such dispersions up to temperatures near the melting temperature and to a frequency of $20 \mathrm{~Hz}$.

2. Experimental processes. - 2.1 Sample charaCTERIZATION. - The samples are characterized by two parameters. The first one is the volume fraction $\Phi$ of the disperse phase (ice-micro-crystals). The second one is the ratio $\rho=\frac{m_{\mathrm{L}}}{m_{\mathrm{L}}+m_{\mathrm{H}}}$, related to the composition of the emulsion medium, in which $m_{\mathrm{L}}$ designates the mass of the emulsifying agent - in the present case, lanolin - and $m_{\mathrm{H}}$ the mass of liquid paraffin, as the emulsion medium is made up of a mixture of lanolin and liquid paraffin.

$\Phi$ is calculated from the respective densities of the components - the density of micro-crystals being assumed to be equivalent to that of macroscopic ice [5] while that of the medium has been measured at various temperatures by the picnometer method. Owing to the variation of these densities with temperature, the parameter $\Phi$ is itself, to a small extent, a function of temperature. To exemplify this, in the case of an emulsion medium characterized by $\rho=1 / 3, \Phi$ varies from 0.333 at $0^{\circ} \mathrm{C}$ to 0.336 at $-20^{\circ} \mathrm{C}$ if the ice weight fraction is 0.35 ; and $\Phi$ varies from 0.382 at $0{ }^{\circ} \mathrm{C}$ to 0.385 at $-20^{\circ} \mathrm{C}$ if the ice weight fraction is 0.40 .

The supercooling ratios are dependent on both $\bar{\Phi}$ and $\rho$, and it seems that the influence of these parameters is felt through the granulometric distribution of the droplets within the medium [6]. Figure 1 shows as an example two curves of granulometric distribution related to water emulsions of the same weight fraction but characterized by differing values of $\rho$. These curves have been determined by means of a Leitz granulometric particle counter from photographs taken with a Zeiss photo-microscope.

As a rule, for an identical weight fraction, the size of the droplets is all the smaller as their environment is richer in emulsifying agent $(d$ : diameter of the droplets).

At the temperatures of our experiments - below $0^{\circ} \mathrm{C}$ - the emulsifying mediums utilized are nearly 

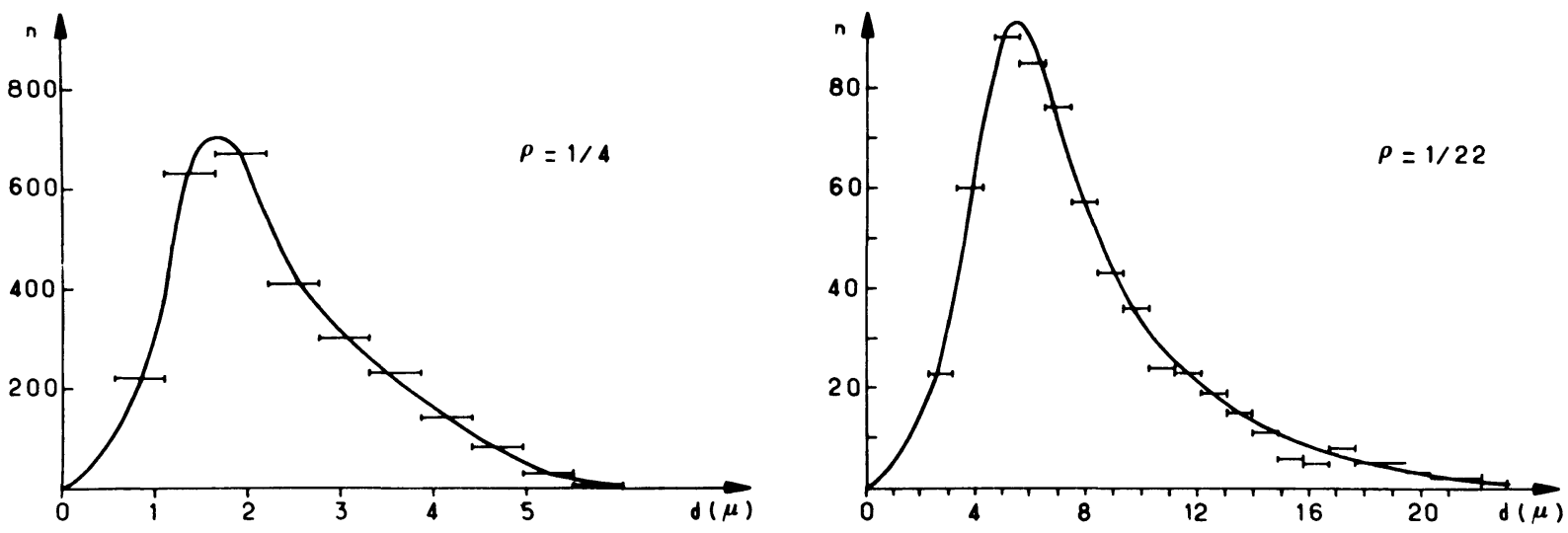

FIG. 1. - Granulometric distribution of dispersions 0.30 in weight fraction.

solid so that, for the times of preservation we have adopted, the decantation and coalescence phenomena are quite negligible.

2.2 TeChNiCal CharaCteristics. - The water utilized is permuted and distilled water, with conductivity around $10^{-5} \Omega^{-1} \mathrm{~m}^{-1}$. The emulsion is obtained by dispersing liquid water within the emulsifying mixture by means of a homogenizer capable of revving at $45.000 \mathrm{rpm}$. The conductivity of the emulsion medium - a mixture of liquid paraffin and lanolin - is negligible in relation to that of water. The emulsion is then introduced into dielectric measurement cells (FERISOL CS 601) which are fully-active condensers whose usable volume is a few $\mathrm{cm}^{3}$.

The measurement cell is placed in a thermistor container and cooled until crystallization of ice is obtained, then raised to a given preservation temperature measured by means of a thermostance. Because of the very great thermal inertia of the cell, the variation in temperature never exceeds $0.1^{\circ} \mathrm{C}$. The experimental values indicated further all correspond to the maximum temperature reached.

The measuring device permitting to evaluate the complex relative permittivity $\varepsilon^{*}$ is made up of two systems of detection and measure of admittance of the Schering-bridge type, covering the range from $20 \mathrm{~Hz}$ to $3 \mathrm{MHz}$. The real $\left(\varepsilon^{\prime}\right)$ and the imaginary $\left(\varepsilon^{\prime \prime}\right)$ parts of $\varepsilon^{*}$ are determined, by means of a method of substitution, with absolute uncertainties that can be valued at $\Delta \varepsilon^{\prime}=0.01$ and $\Delta \varepsilon^{\prime \prime}=0.01$.

3. Determination of the irreversibility ratio of ice micro-crystals. - 3.1 DETECTION OF CRYSTALLIZATION. - Supercooling breakdown of water can be studied either by differential thermal analysis or by differential enthalpic analysis or by dilatometry; hertzian spectroscopy, too, can be used by following the variations of the dielectric constant as a function of temperature $[1,7]$.

In the latter case, it is advisable to measure the permittivity $\varepsilon^{\prime}$ of the dispersion for a high frequency of the electric field here applied, comprised between $100 \mathrm{kHz}$ and $1 \mathrm{MHz}$. Effectively, at such frequencies, the dielectric constant of macroscopic ice is around 3.08 [8], whereas that of liquid water - equivalent to 88 at $T=0{ }^{\circ} \mathrm{C}$ - is 91.6 at $T=-10^{\circ} \mathrm{C}$ (in supercooled state) and seems to be a decreasing function of temperature [9].

Because of this great difference between the permittivity of water and that of ice in great volume and at high frequencies, crystallization can be observed easily, even on the emulsions, as it is revealed by a sharp decrease of $\varepsilon^{\prime}$, the real part of the complex permittivity $\varepsilon^{*}$. This method has been utilized to study the monothermal congelation of supercooled water $[10,11]$. We have also made use of it in the field of our experiments.

3.2 ReSults. - It is currently admitted that supercooling breakdown of water droplets occurs at a temperature that is all the lower as the diameter of the droplets is smaller. Nevertheless, with the emulsifying agent utilized, the limit supercooling ratio observed is $38^{\circ} \mathrm{C} \pm 1{ }^{\circ} \mathrm{C}$ [12].

What can be evaluated from the curves $\varepsilon^{\prime}(T)$ is not the temperature(s) of supercooling breakdown because of the amplitude of these curves - but temperature intervals within which total or partial freezing of the samples occurs.

Figure 2 relating to water emulsions that are 0.20 $0.30-0.40-0.50$ in weight fraction, shows that in some cases freezing is total within a narrow temperature interval, that in other cases the interval is larger and, finally, that it is possible to observe two distinct ranges of crystallization temperature.

The object of the present work was not a systematic study of the correlations between the granulometric distribution of droplets within the emulsions and their rates of supercooling. An exhaustive bibliography on the phenomenon of supercooling is given in [13]. However, it seems that, when the distribution of droplets as a function of their size is selective, freezing is observed in a narrow temperature range whose position depends on the more probable size. Reversely, the widening of granulometric distribution seems to result in a wider range of crystallizing temperature. 

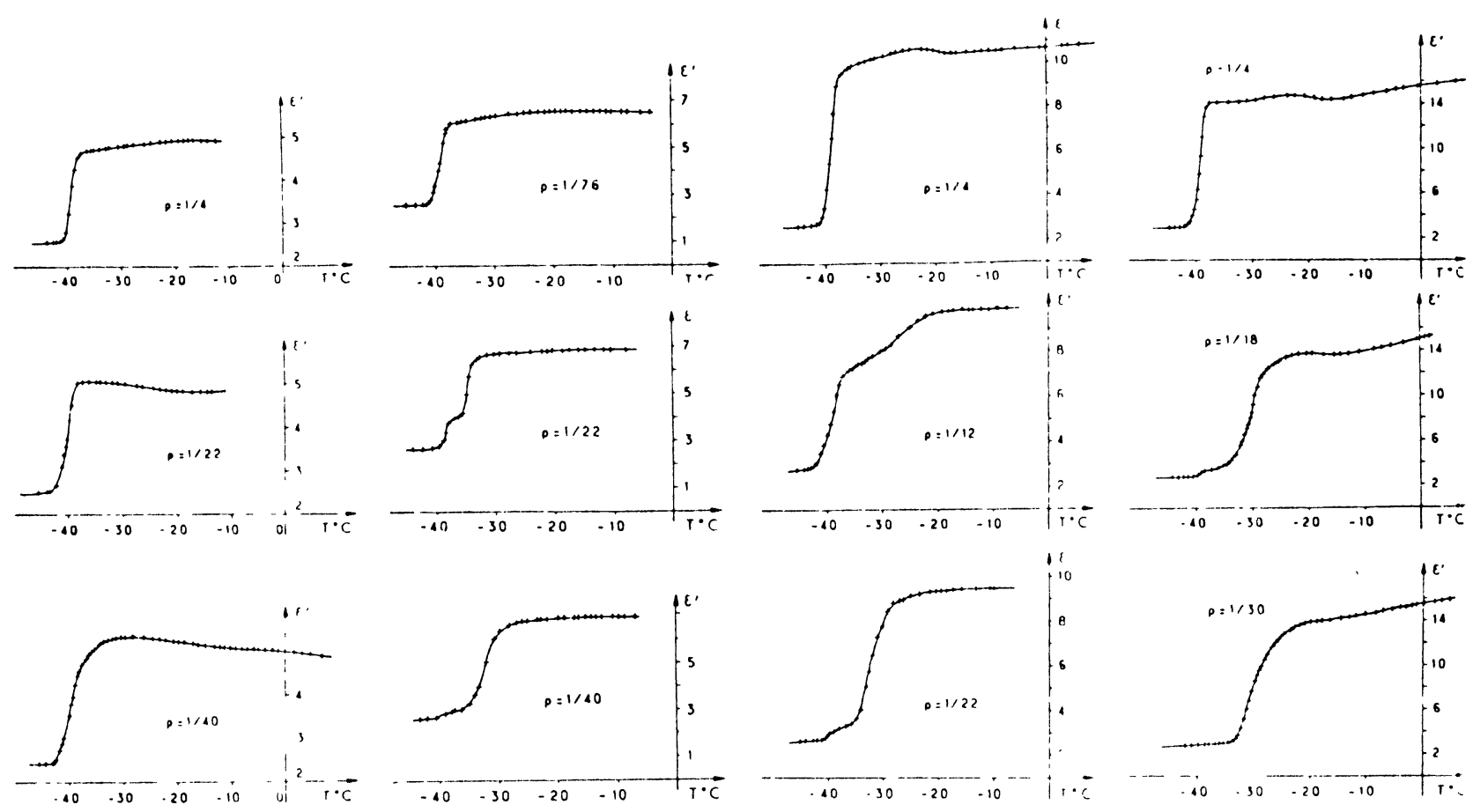

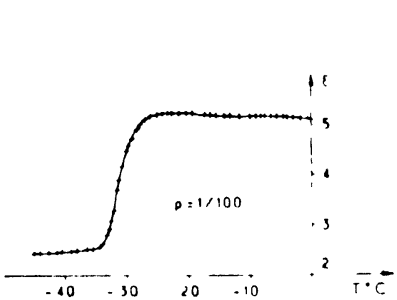

(a)

Weight fraction : 0.20

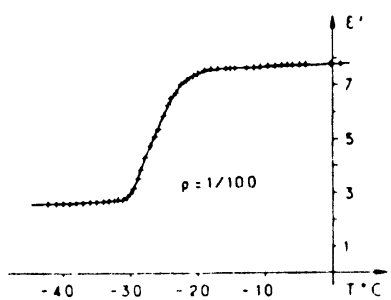

(b)

Weight fraction : 0.30

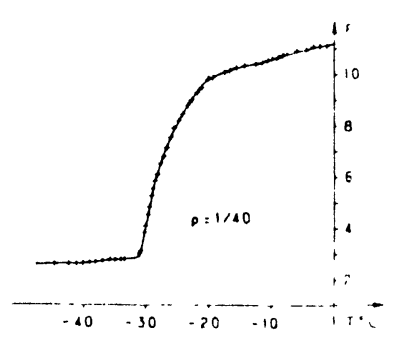

(c)

Weight fraction : 0.40

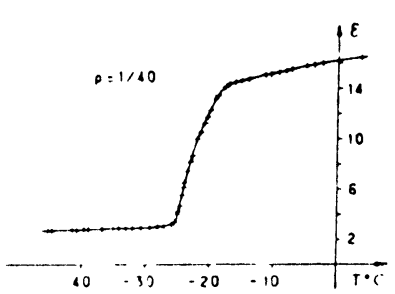

(d)

Weight fraction : 0.50

FIG. 2. - Determination of crystallization.

In all cases, permittivity $\varepsilon^{\prime}$ tends towards a lower limit that we shall call limit permittivity in high frequencies $\varepsilon_{\mathrm{d}}^{\prime}$ of ice dispersion. Reversely, the phenomenon of fusion results in a sharp increase of the sample's permittivity $\varepsilon_{\mathrm{d}}^{\prime}$.

\section{General characteristics of the dielectric relaxation} presented by the dispersion of ice micro-crystals. 4.1 DESCRIPTION OF THE PHENOMENON. - Directly after freezing, each sample is brought to and maintained at a fixed temperature $T$ about $-8^{\circ} \mathrm{C}$.

The temperature of the sample can be read in a continuous way. When the mark on the thermometric device ceases to vary, one should wait a further ten minutes or so after which the temperature, then stabilized, can be evaluated with an approximation of $1 / 10$ of a degree. Permittivity $\varepsilon^{*}$ is then measured for various values of the frequency.

Figure $3 a$ shows that, when the frequency $v$ of the electric field applied increases, $\varepsilon^{\prime}$ decreases from the value $\varepsilon_{l}^{\prime}$ on, then goes on to a level stage, $\varepsilon_{\mathrm{s}}^{\prime}$, that is reached for a frequency of a few kilohertz and, finally, after a further decrease, reaches the limit value $\varepsilon_{\mathbf{d}}^{\prime}$ related to high frequencies. The variations of $\varepsilon^{\prime \prime}$ are shown by a curve with two maxima : $\varepsilon^{\prime \prime}$ starts from a value near 0 , passes by a maximum, then by a minimum before passing again by a maximum to eventually tend towards 0 . The pattern of the two curves $\varepsilon^{\prime}(\log v)$ and $\varepsilon^{\prime \prime}(\log v)(\log v$ : decadic logarithm) is similar to that which would be given by two Debye dipolar absorptions - with the ColeCole plot $\varepsilon^{\prime \prime}=f\left(\varepsilon^{\prime}\right)$ appearing in the form of two arcs of a circle slightly coupled, whose centres are below the $\varepsilon^{\prime}$ axis (Fig. $3 b$ ). The two maxima of $\varepsilon^{\prime \prime}$ are obtained for the particular frequencies $v_{\mathbf{c}_{1}}$ and $v_{\mathbf{c}_{2}}\left(v_{\mathbf{c}_{1}}>v_{\mathbf{c}_{2}}\right)$, determined from Smyth's method [14]. If we carry $\log v / w$ as a function of $\log v$ on a plot $v$ designating the distance from one point on the arc of a circle to the point with the co-ordinates $\left(\varepsilon_{s}^{\prime}, O\right)$, and $w$ the distance from the same point to the point with the co-ordinates $\left(\varepsilon_{\mathrm{d}}^{\prime}, O\right)$ (see Fig. 4$), v$ being the frequency corresponding to the running point of the arc - the representative points determine a curve whose intersection with the $x$-axis provides the values of the decadic logarithm of the frequency of maximum absorption, $\log v_{\mathrm{c}_{1}}$. The value obtained by this method is determined to an approximation of 0.01 .

$\log v_{\mathbf{c}_{2}}$ is determined in the same way. When the parametering in frequency of the points on the arc of the circle is identical with that corresponding to a Debye dipolar absorption with relaxation times distributed along a Cole-Cole type distribution [15], 


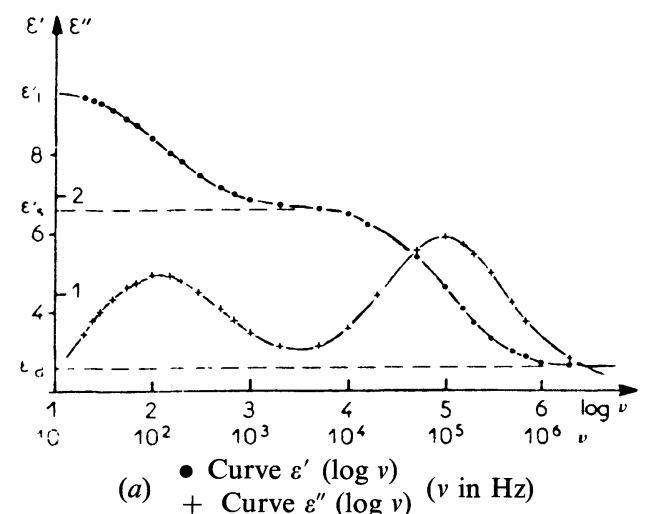

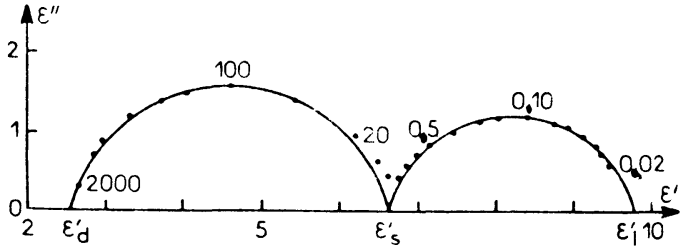

(b) : Curve $\varepsilon^{\prime \prime}\left(\varepsilon^{\prime}\right) \quad(v$ in $\mathrm{Hz})$

FIG. 3. $-\Phi=0.24 ; \rho=\frac{1}{6}$.

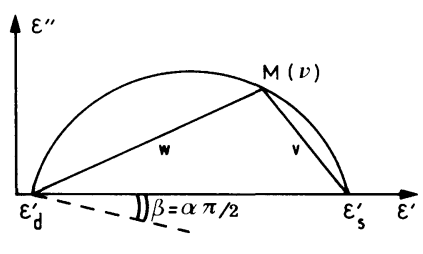

FIG. 4.

the representative points are plotted according to an equation line :

$$
\log \frac{v}{w}=(1-\alpha) \log v-(1-\alpha) \log v_{\mathrm{c}}
$$

the coefficient $\alpha$ being that used in the expression of the complex permittivity :

$$
\varepsilon^{*}=\varepsilon_{\mathrm{d}}^{\prime}+\frac{\varepsilon_{\mathrm{s}}^{\prime}-\varepsilon_{\mathbf{d}}^{\prime}}{1+j \omega \bar{\tau}^{(1-\alpha)}} .
$$

The values of the quantities $\varepsilon_{l}^{\prime}, \varepsilon_{\mathrm{s}}^{\prime}, \varepsilon_{l}^{\prime}-\varepsilon_{\mathrm{s}}^{\prime}, \varepsilon_{\mathrm{s}}^{\prime}-\varepsilon_{\mathrm{d}}^{\prime}$ are dependent on the two parameters $\rho$ and $\Phi$. So is it with the frequencies $v_{\mathrm{c}_{1}}$ and $v_{\mathrm{c}_{2}}$. On the contrary, the variations of $\varepsilon_{\mathrm{d}}^{\prime}$ are very small when these parameters vary : effectively, $\varepsilon_{\mathrm{d}}^{\prime}$ passes from 2.44 for $\Phi=0.19$ to 2.48 for $\Phi=0.29$, and to 2.55 for $\Phi=0.385$ in an emulsion medium characterized by $\rho=\frac{1}{4}$. Similarly, $\varepsilon_{\mathrm{d}}^{\prime}$ varies from 2.47 for $\rho=\frac{1}{2}$ to 2.50 for $\rho=\frac{1}{15}$, with the water weight fraction equal to 0.25 .
4.2 INFLUENCE OF PARAMETERS $\rho$ AND $\Phi$. a) Influence of $\Phi$ with $\rho$ being fixed. - The permittivities $\varepsilon_{l}^{\prime}$ and $\varepsilon_{\mathrm{s}}^{\prime}$ and the quantities $\varepsilon_{l}^{\prime}-\varepsilon_{\mathrm{s}}^{\prime}$ and $\varepsilon_{\mathrm{s}}^{\prime}-\varepsilon_{\mathrm{d}}^{\prime}$ are increasing functions of $\Phi$ with $\rho$ being fixed, as is shown in figure 5. Therefore, an increase in the percentage of ice micro-crystals entails both a displacement of the centres with a variation of the decentring and an increase of the radius of the Cole-Cole plots (Fig. 5).

On the contrary, the frequencies $v_{\mathrm{c}_{1}}$ and $v_{\mathrm{c}_{2}}$ are decreasing functions of $\Phi$.

b) Influence of $\rho$ with $\Phi$ being fixed. $-\varepsilon_{l}^{\prime}$ and $\varepsilon_{l}^{\prime}-\varepsilon_{\mathrm{s}}^{\prime}$ increase as $\rho$ decreases. So is it with $\varepsilon_{\mathrm{s}}^{\prime}$, but the amplitude of the variation is much smaller (Fig. 6).

The frequencies $v_{\mathrm{c}_{1}}$ and $v_{\mathrm{c}_{2}}$ are increasing functions of $\rho$. Figure 7 shows that the variations of $v_{\mathrm{c}_{2}}$ as a function of $\rho$ are particularly important : in effect, $v_{\mathrm{c}_{2}}$ passes from $2400 \mathrm{~Hz}$ for $\rho=\frac{1}{2}$ to $7.25 \mathrm{~Hz}$ (this value being obtained through an extrapolation) for $\rho=\frac{1}{30}$ in the case of dispersions of an ice weight fraction of 0.25 - with the common temperature throughout the study being $\mathrm{T}=-8^{\circ} \mathrm{C}$. The variations of $v_{\mathrm{c}_{1}}$, though being of lesser amplitude, are not negligible, as this frequency passes from $270 \mathrm{kHz}$ for $\rho=\frac{1}{2}$ to $30.2 \mathrm{kHz}$ for $\rho=\frac{1}{30}$.

5. Evolution of relaxation in course of time. 5.1 After maintaining the sample at $-8{ }^{\circ} \mathrm{C}$ for several days, a further measurement of $\varepsilon^{*}(v)$ shows

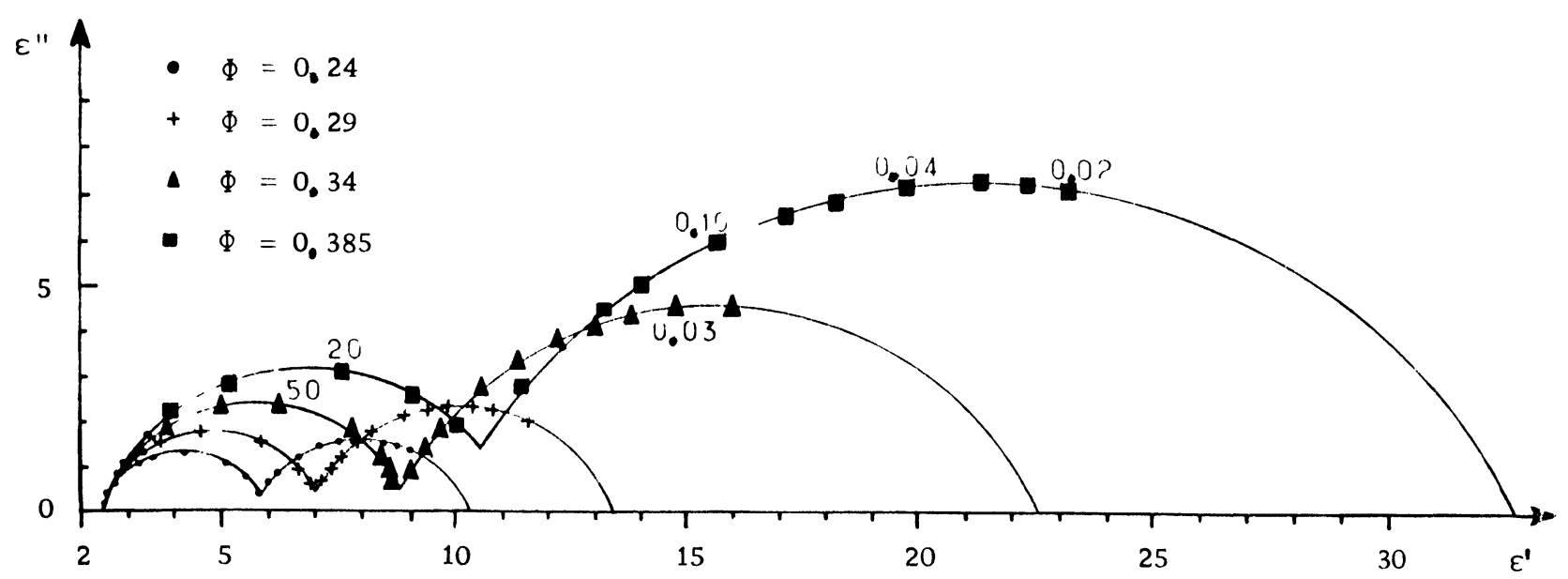

FIG. 5. - Plots $\varepsilon^{\prime \prime}\left(\varepsilon^{\prime}\right)$ for various values of $\Phi$ at $T=-8{ }^{\circ} \mathrm{C}$ and for $\rho=\frac{1}{10}(v \mathrm{in} \mathrm{kHz})$. 


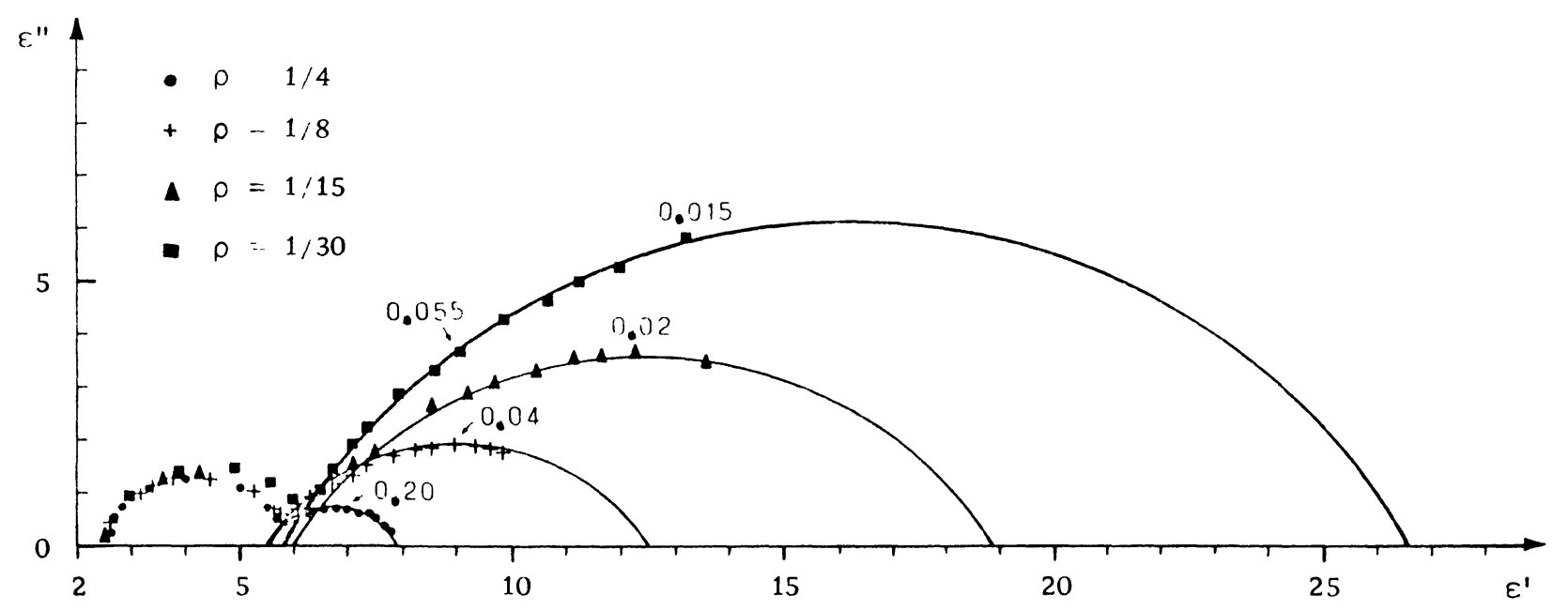

FIG. 6. - Plots $\varepsilon^{\prime \prime}\left(\varepsilon^{\prime}\right)$ for various values of $\rho$ at $T=-8{ }^{\circ} \mathrm{C}$ and for a weight fraction $0.25(v \mathrm{in} \mathrm{kHz})$.

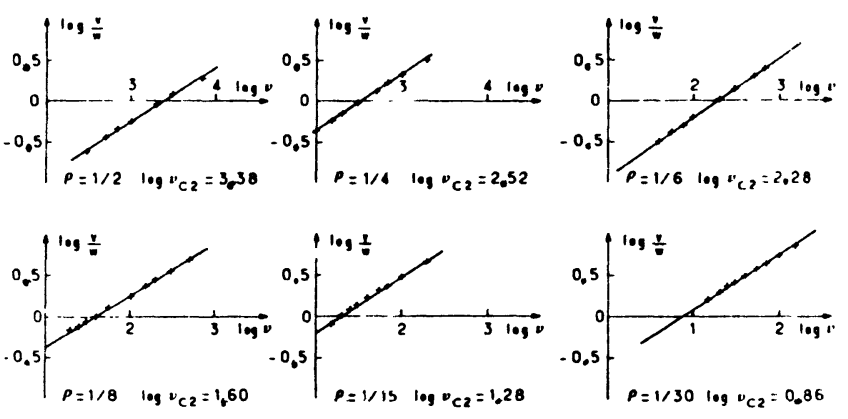

FIG. 7. - Variations of $v_{\mathrm{c}_{2}}$ as a function of $\rho$, at $T=-8^{\circ} \mathrm{C}$ $(v$ in $\mathrm{Hz})$.

that the Cole-Cole plot presents differences from the initial plot.

The value of $\varepsilon_{\mathrm{d}}^{\prime}$ remains unchanged. On the contrary, the permittivities $\varepsilon_{l}^{\prime}$ and $\varepsilon_{\mathbf{d}}^{\prime}$ have decreased slightly, as $v_{\mathrm{c}_{1}}$ and $v_{\mathrm{c}_{2}}$ have increased. However, this evolution remains limited as regards the amplitude of its effects. Thus, for a dispersion $\Phi=0.39$ with $\rho=\frac{1}{3}, \varepsilon_{l}^{\prime}$ passes from 16.40 to 15.90 , whereas $\varepsilon_{\mathrm{s}}^{\prime}$ decreases from 10.24 to 10.10 .

5.2 If the sample is brought to a preservation temperature between $-3^{\circ} \mathrm{C}$ and $0^{\circ} \mathrm{C}$, there occurs an extremely fast evolution whose effects are on the whole identical with those just described, but of materially greater amplitude, as is shown in figures 8 $(a, b, c)$.

After preserving the sample for several days at a temperature near melting temperature, the permittivities $\varepsilon_{l}^{\prime}$ and $\varepsilon_{\mathrm{s}}^{\prime}$ tend towards limit values, as well as $v_{\mathrm{c}_{1}}$ and $v_{\mathrm{c}_{2}}$. Here it should be noted that the constancy of $\varepsilon_{\mathrm{d}}^{\prime}$ shows well that there is no fusion of the crystal lattice, whereas the evolutive phenomenon is fully manifested as soon as the temperature is higher than $-3^{\circ} \mathrm{C}$.

5.3 The series of measurements relating to figure $8 c$ is particularly interesting. The characteristics of the dispersion studied $\left(\Phi=0.28, \rho=\frac{1}{3}\right)$ are in fact such that $v_{\mathrm{c}_{1}}$ and $v_{\mathrm{c}_{2}}$ are very high. Within the range of frequencies available with our device $(20 \mathrm{~Hz}-3 \mathrm{MHz})$, the plot $\varepsilon^{\prime \prime}\left(\varepsilon^{\prime}\right)$ obtained at $-8^{\circ} \mathrm{C}$ immediately after crystallization is made up of two parts, as has just been shown. It is sufficient to bring the dispersion to $-1^{\circ} \mathrm{C}$ for some time to modify the field of absorption thoroughly and to notice in the plot $\varepsilon^{\prime \prime}\left(\varepsilon^{\prime}\right)$ the existence of a third field, of which only the start is evidenced, because of the lower limit of our device. We will show further the behaviour followed by this third field of absorption which we have been able to bring to light only with a very high proportion of emulsifying agent.

6. Study of the influence of temperature - We have just pointed out that, after preserving the samples for a few days near melting temperature, the dielectric properties of the dispersions of ice crystals become stabilized, as regards $\varepsilon_{l}^{\prime}, \varepsilon_{\mathrm{s}}^{\prime}$ and $\varepsilon_{\mathrm{d}}^{\prime}$, as well as $v_{\mathrm{c}_{1}}$ and $v_{\mathrm{c}_{2}}$. The influence of temperature on $\varepsilon^{*}(v)$ has been studied once this stabilization is attained. To this end, we have subjected the samples to a series of measurements effected at fixed temperature and variable frequency, within the temperature range from $0^{\circ} \mathrm{C}$ to $-60^{\circ} \mathrm{C}$. The experience has shown that three temperature ranges should be distinguished : from $0{ }^{\circ} \mathrm{C}$ to about $-10^{\circ} \mathrm{C}$, from $-10^{\circ} \mathrm{C}$ to about $-20^{\circ} \mathrm{C}$ or $-25^{\circ} \mathrm{C}$, and the lower temperatures.

It is important finally to note that the effects of temperature are reversible once the evolution is completed; in fact, measurements achieved by means of heating yield the same results.

6.1 INFLUENCE OF TEMPERATURE ON THE PATTERN OF THE PLOTS $\varepsilon^{\prime \prime}\left(\varepsilon^{\prime}\right)$. - $\left.-a\right)$ Near-fusion temperatures $\left(0^{\circ} \mathrm{C},-10^{\circ} \mathrm{C}\right)$ : both ranges of relaxation, still clearly distinct at $-8^{\circ} \mathrm{C}$ (Fig. 9), present increasing co-ordination as higher and higher temperatures are utilized, to result in one single arc of a circle at $0^{\circ} \mathrm{C}$.

The junction area between both ranges, which initially corresponds to a minimum of $\varepsilon^{\prime \prime}$, gradually 

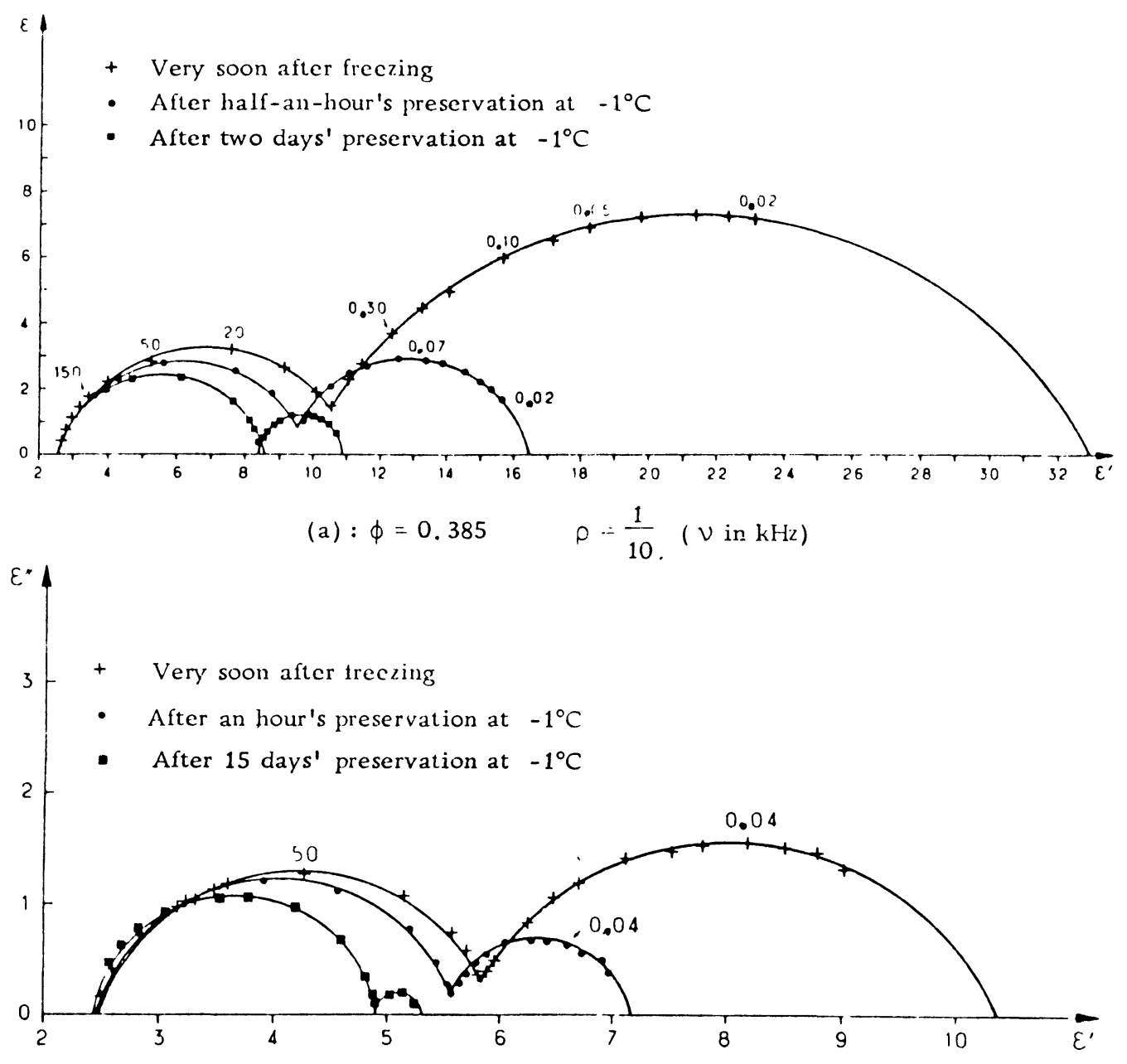

(b) : $\phi=0.24 \quad \rho-\frac{1}{10}(\nu$ in $\mathrm{kHz})$
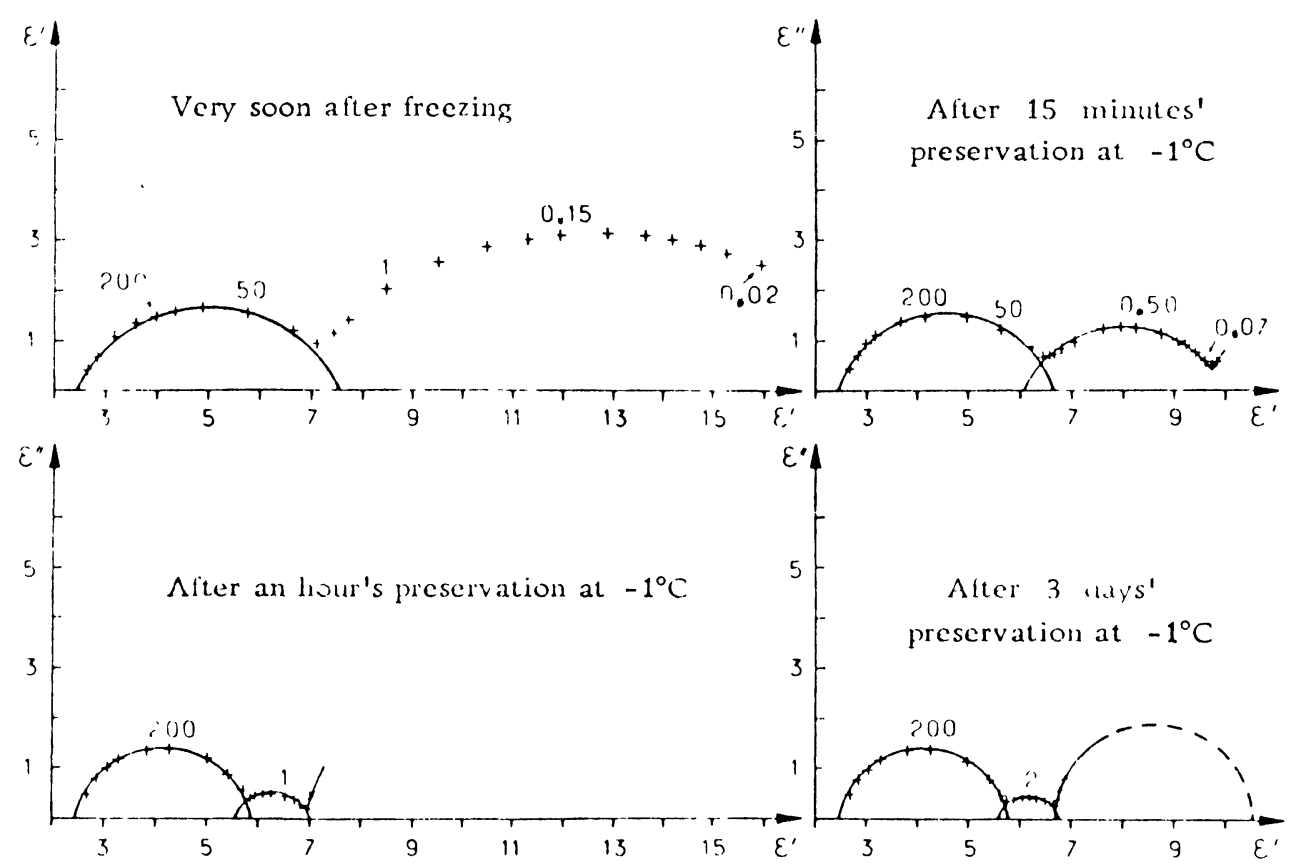

(c) : $\Phi=0.28 \quad \rho=\frac{1}{3} \quad(v$ in $\mathrm{KHz})$

FIG. 8. - Variations in course of time of the plot $\varepsilon^{\prime \prime}\left(\varepsilon^{\prime}\right): T=-8^{\circ} \mathrm{C}$. 

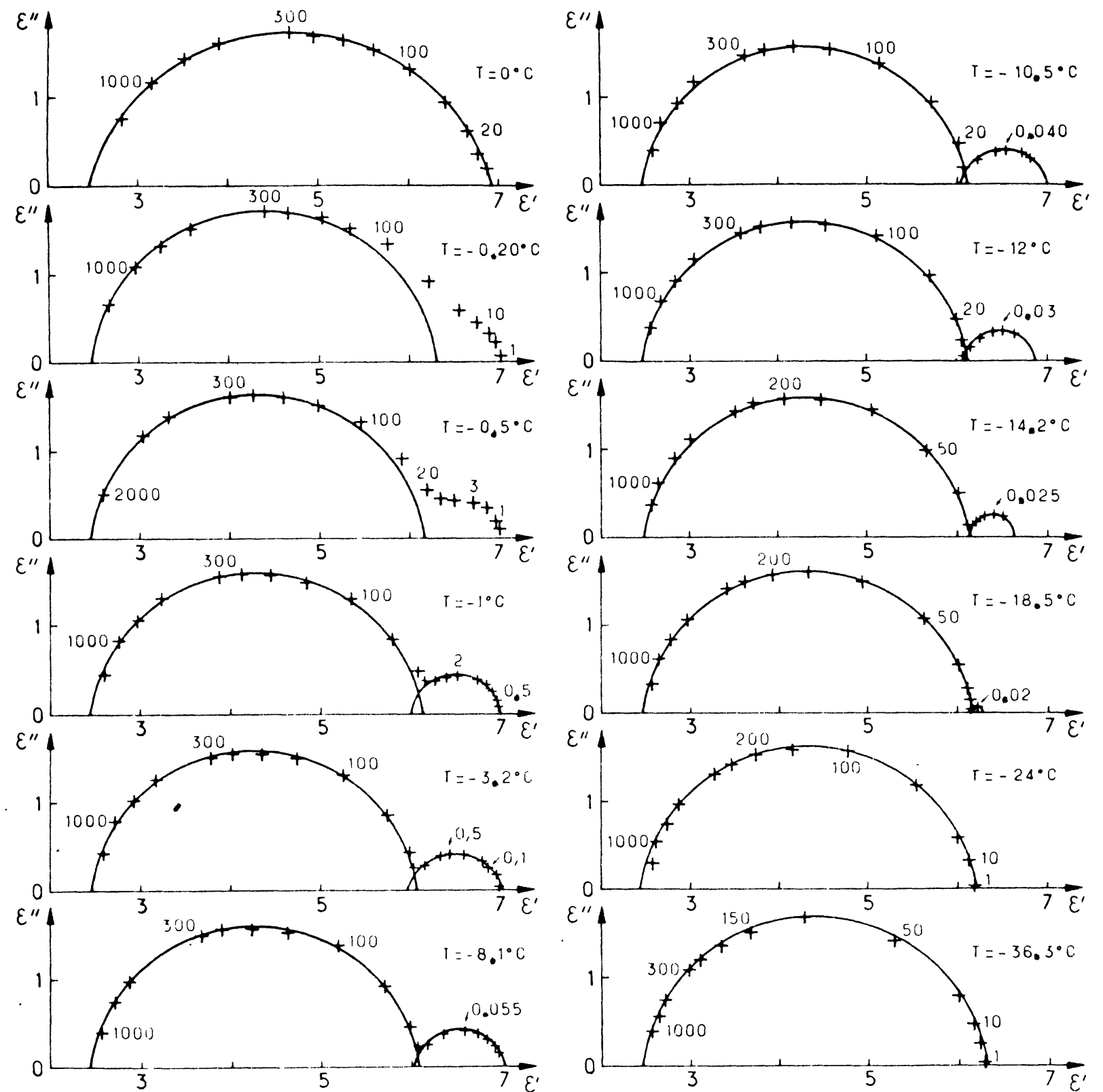

FIG. 9. - Variations of the plot $\varepsilon^{\prime \prime}\left(\varepsilon^{\prime}\right)$ with temperature, in the case of a dispersion $\Phi=0.33 ; \rho=1 / 40(v$ in $\mathrm{kHz})$.

becomes an inflexion and eventually merges into the single arc of the circle.

The values of $\varepsilon_{l}^{\prime}$ and $\varepsilon_{\mathrm{d}}^{\prime}$ are not dependent on temperature and correspond to the two limit values of the single arc at $0^{\circ} \mathrm{C}$. Parametering in frequency is, on the contrary, materially affected by $T$, more particularly in the near vicinity of $0^{\circ} \mathrm{C}$ (see next paragraph).

b) Temperatures between $-10^{\circ} \mathrm{C}$ and about $-20^{\circ} \mathrm{C}$ : within this range, the field related to the higher frequencies $\left(v_{\mathrm{c}_{1}}\right)$ is not noticeably modified. The value of $\varepsilon_{\mathrm{d}}^{\prime}$ remains constant, that of $\varepsilon_{\mathrm{s}}^{\prime}$ is slightly dependent on $T$ (with a slight increase as $T$ decreases); likewise, $v_{\mathrm{c}_{1}}$ decreases slightly under the same conditions.

On the contrary, the characteristics of the second field - with an absorption frequency of $v_{\mathrm{c}_{2}}$ - are materially dependent on temperature. As $T$ decreases, $\varepsilon_{l}^{\prime}$ tends towards $\varepsilon_{\mathrm{s}}^{\prime}$ (Fig. 9), whereas the centre of the arc of a circle located in the area $\varepsilon^{\prime \prime}<0$ for the higher temperatures rises towards the $\varepsilon^{\prime}$ axis as $T$ decreases, entailing a fall of the decentring parameter $\alpha$ (determined from the angle $\alpha \pi / 2$ shown on Fig. 4). Finally, the value of $\varepsilon^{\prime \prime}$ corresponding to the maximum absorption of this second field decreases with $T$ (see Fig. 9).

c) Temperatures lower than $-20^{\circ} \mathrm{C}$ or so : it is no longer possible to evidence the second field, which seems to have disappeared completely. There only remains the field of high frequencies, whose evolutive properties in course of time and under the influence of temperature have been the matter of recent studies, as we have already mentioned.

In figure 10 , finally, we can see the variations of $\varepsilon^{\prime \prime}$ as a function of $\log v$ for various temperatures. 


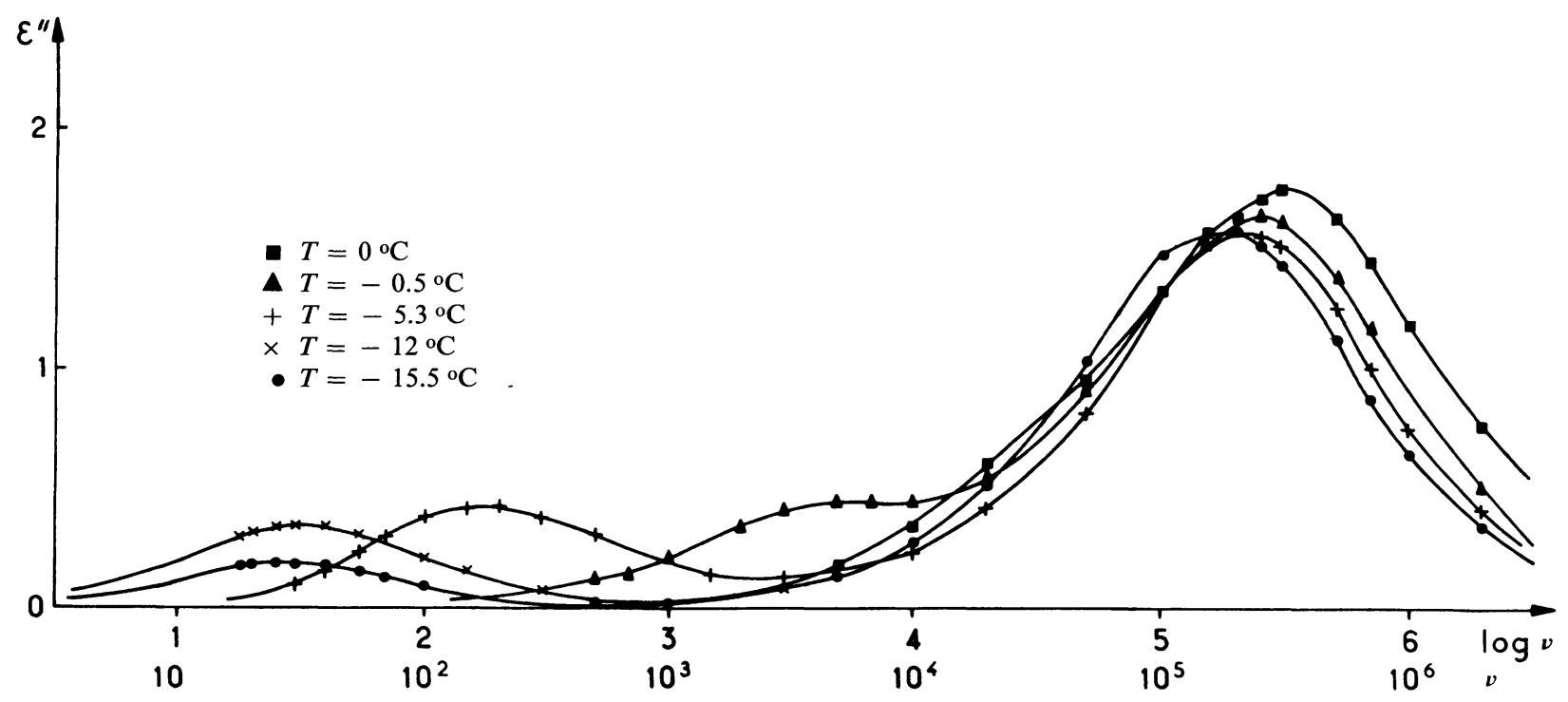

Fig. 10. - Curves $\varepsilon^{\prime \prime}(\log v)$ for various temperatures $(v$ in $\mathrm{Hz})$.

6.2 VARIATIONS OF $v_{\mathrm{c}_{1}}$ AND $v_{\mathrm{c}_{2}}$ WITH TEMPERATURE. - a) With the help of Smyth's method and knowing the Cole-Cole plots, we have determined $v_{\mathrm{c}_{1}}$ and $v_{\mathrm{c}_{2}}$ for each temperature $T$ under study. Figure 11 represents the plots $\left(\log v_{\mathrm{c}}, 1 / T\right)$ for the two fields of absorption.

At temperatures lower than $-20^{\circ} \mathrm{C}$ or so, for which only the first field of relaxation can be observed, the experimental points are in a line, which means that $v_{\mathrm{c}_{1}}$ obeys a law of the type

$$
v_{\mathrm{c}_{1}}=A \exp \left[-\frac{U}{k T}\right],
$$

$U$ designating the activation energy of the Debye dipolar relaxation of disperse ice [3]. According to the samples studied, it has been found to be comprised between $0.16 \mathrm{eV}$ and $0.40 \mathrm{eV}$.

In the case of figure 11, we can for instance obtain : $U=(0.18 \pm 0.01) \mathrm{eV}$. At temperatures higher than $-20^{\circ} \mathrm{C}$, the plot $\left(\log v_{\mathrm{c}}, 1 / T\right)$ is composed of two curved parts relating to each field. As the points are not in a line, we cannot determine an activation energy, but we can notice the very close dependence of $v_{\mathrm{c}_{2}}$ on temperature when getting near melting temperature.

Taking into account the existence of a single relaxation at $0^{\circ} \mathrm{C}$ that merges the two fields of absorption, both curves present one common point at this temperature. Besides, this particular point is practically located on the prolongation of the line of absorption relating to the first field (Fig. 11).

Figure 12, in which we have plotted the curves $\log v / w=F(\log v)$ corresponding to the second field of absorption, shows that these are straight lines just as for the first field. But, whereas we can for the latter infer a distribution in frequency of the ColeCole type - by comparing the values of $\alpha$ as determined from the slope of the line represented by

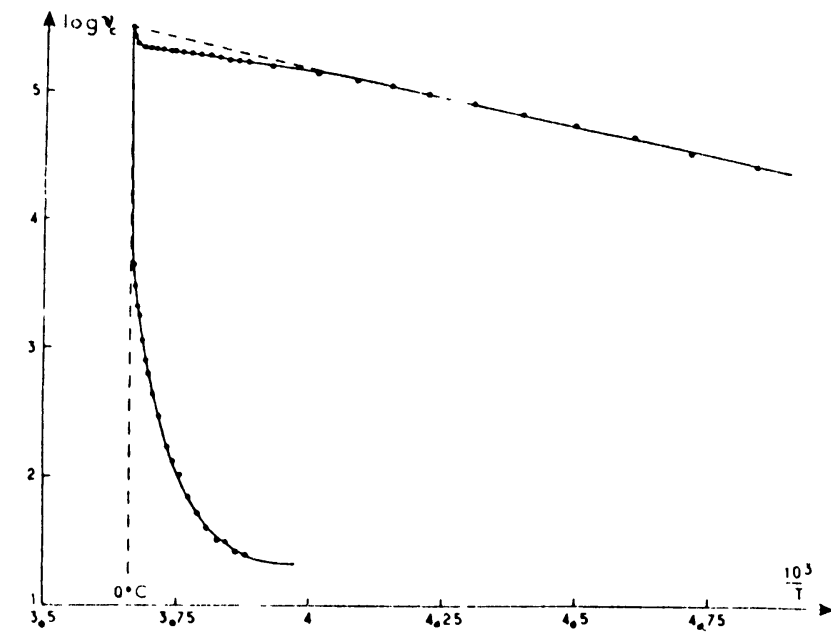

FIG. 11. - Plots $\left(\log v_{\mathrm{c}}, \frac{1}{T}\right)\left(v_{\mathrm{c}}\right.$ in $\mathrm{Hz}, T$ in degrees $\left.\mathrm{K}\right)$.

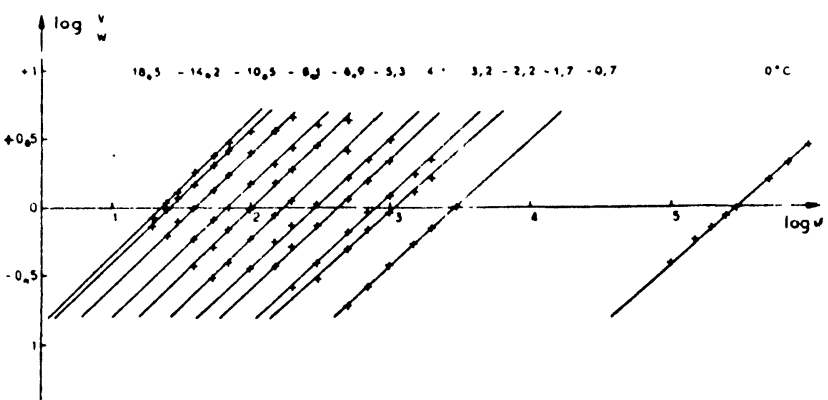

FIG. 12. - Determination of $v_{\mathbf{c}_{2}}(v$ in $\mathrm{Hz})$.

relation (1) and from the angle $\pi \alpha / 2$ - the fact that the lines maintain a fairly constant slope despite the decrease of the angle $\pi \alpha / 2$ with temperature reveals that the distribution of the points in frequency in the second field is not of the Cole-Cole type.

7. Behaviour of the third field of relaxation. - In most cases, if we utilize emulsion mediums with only little emulsifying agent, we can observe two fields 


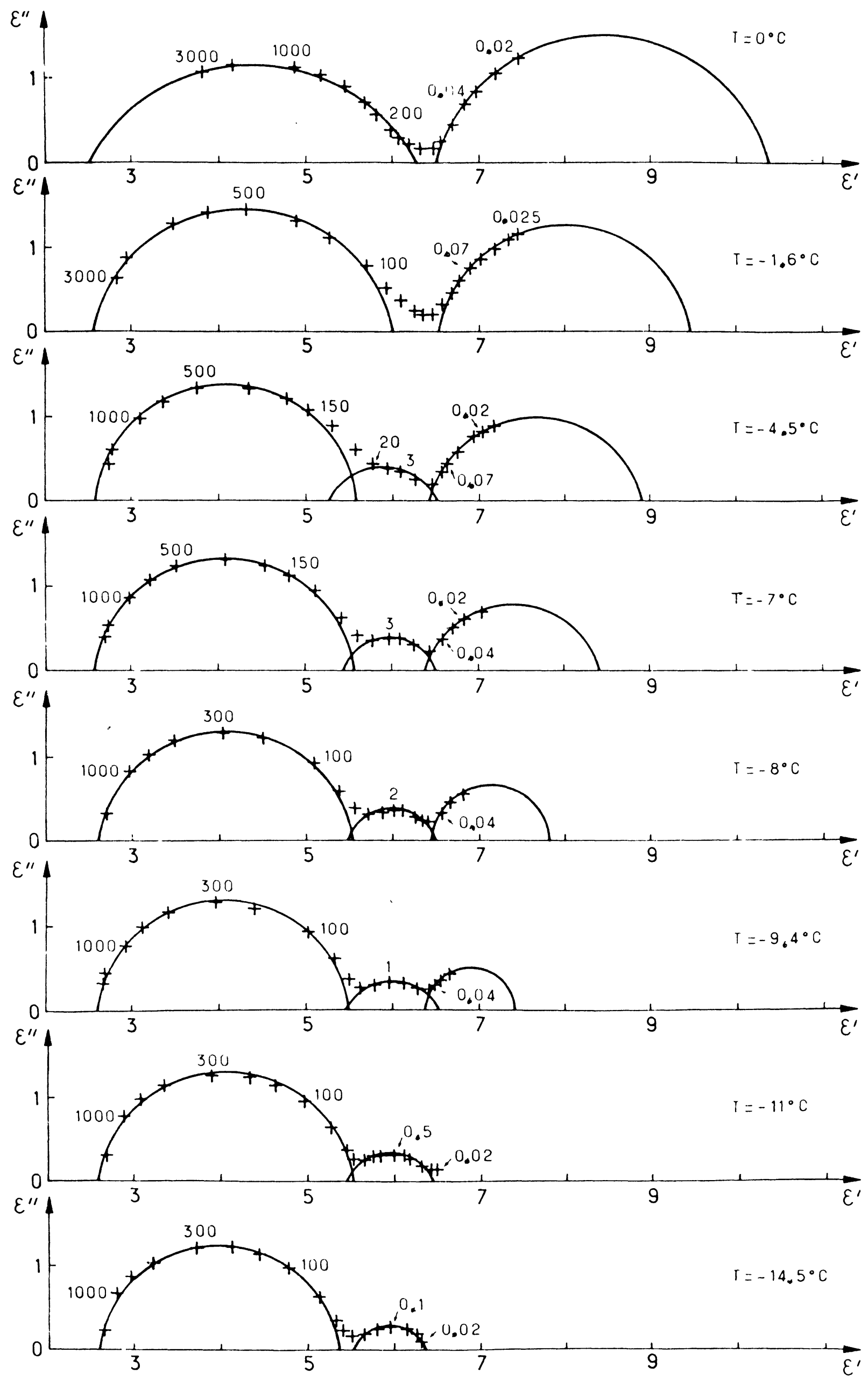

Fig. 13. - Variations with temperature of the plot $\varepsilon^{\prime \prime}\left(\varepsilon^{\prime}\right)$ in the case of a dispersion $\Phi=0.29 ; \rho=2 / 3(v$ in $\mathrm{kHz})$. 
of relaxation which are fully covered in the range of frequency utilized, at least at the higher temperatures.

We have mentioned above that, when the proportion of emulsifying agent is very high, we can evidence the start of a third field of absorption, whose behaviour has been studied as a function of temperature. Figure 13 relates to a sample with the characteristics $\Phi=0.29$ and $\rho=\frac{2}{3}$. At $0{ }^{\circ} \mathrm{C}$, the plot $\varepsilon^{\prime \prime}\left(\varepsilon^{\prime}\right)$ is composed of two arcs of a circle. If temperature $T$ is lowered, we can gradually observe the decoupling of the arc with the higher frequency into two distinct fields of relaxation, in accordance with figure 9. Along with this decoupling, the third field related to the lower frequencies varies with $T$ in a continuous way. Its dimensions decrease, as does the value of $\varepsilon^{\prime \prime}$ of the maximum absorption, while the parameter $\alpha$ related to this field tends towards 0 .

The disappearance of this third field seems to be effective about $-11^{\circ} \mathrm{C}$, its dimensions then becoming inferior to the limit of resolution of the device. Within the temperature range from $0^{\circ} \mathrm{C}$ to $-11^{\circ} \mathrm{C}$, the first two fields have behaved in accordance with what has been discussed before, that is to say only the frequencies $v_{\mathrm{c}_{1}}$ and $v_{\mathrm{c}_{2}}$ and also the coupling have varied. Below $-11^{\circ} \mathrm{C}$, the phenomena are here again identical with those mentioned above : disappearance of the second field about $-25^{\circ} \mathrm{C}$, then observation of only the field related to the Debye dipolar absorption of ice at the lower temperatures.

It is important to point out that complementary experiments show that these results are independent from the nature of the emulsion medium, provided this should be an insulating one - for instance by using Span 85 as an emulsifying agent.

8. Conclusions. - From these experimental results as a whole, it emerges that, at temperatures higher than $-20^{\circ} \mathrm{C}$ or so, we can observe fields of relaxation which are added to the one produced by the Debye dipolar absorption of ice - their importance apparently increasing with temperature.

The systems studied are complex ones, since we are dealing with dispersions of ice micro-crystals obtained by an irreversible process. In addition, as the number of micro-crystals by $\mathrm{cm}^{3}$ of sample is very high, the surface ice/environment is very large.

In the second section of this study, we will propose an interpretation based on the assumption of the existence of a phenomenon of prefusion of microcrystals, which takes into account possible surface effects.

\section{References}

[1] Babin, L., Thèse de Doctorat ès Sciences Physiques, Bordeaux (1966).

[2] Evrard, G., Phys. and Chem. of Ice (ed. by Whalley, Jones, Gold, Royal Society of Canada, Ottawa) 1973, p. 199.

[3] Clausse, M., C. R. Hebd. Séan. Acad. Sci. 275 B (1972) 427.

[4] Boned, C., J. Physique 37 (1976) 165.

[5] Lliboutry, L., Traité de glaciologie, Tome I (Masson et Cie) 1964, 22.

[6] Heverly, J. R., Trans. Am. Geophys. Un. 30 (1949) 205.

[7] Chapman, I. D., J. Phys. Chem. 72 (1968) 33.

[8] Auty, R. P., Cole, R. H., J. Phys. Chem. 20 (1952) 1309.
[9] HASTED, J. B., Water, a comprehensive treatise : Volume 1 (ed. by Felix Franks, Plenum press) 1972, p. 255.

[10] Lachaise, J., C. R. Hebd. Séan. Acad. Sci. 274 B (1972) 1095.

[11] Lachaise, J., Clausse, M., J. Phys. D : Appl. Phys. 8 (1975) 1227.

[12] Boned, C., Diplôme d'Etudes Supérieures, Pau (1967).

[13] Clausse, D., Thèse de Doctorat ès Sciences Physiques, Pau (1972).

[14] SмYTH, C. P., Dielectric behaviour and structure (Mc Graw-Hill) 1955.

[15] Cole, K. S., Cole, R. H., J. Phys. Chem. 9 (1949) 341. 